\title{
THE APPLICATION OF MODERN METHODS OF CALCULATION IN FOUNDRY PRODUCTION
}

\author{
Martina ZÁVRBSKÁ, Petr BESTA, Adam DRASTICH \\ VSB - Technical University of Ostrava, Faculty of Materials Science and Technology Ostrava, \\ Czech Republic,EU, martina.zavrbska.st@vsb.cz, petr.besta@vsb.cz, adam.adrastich.st@vsb.cz
}

https://doi.org/10.37904/metal.2021.4285

\begin{abstract}
The current business environment is characterized by the constantly changing needs and wishes of customers, technological progress and growing competition. A company which wants to maintain its position on the market must actively work to maintain and increase its competitiveness. A key method of gaining a sustainable competitive advantage is through effective cost management. The basic pillar of cost management is extensive data collection and continuous optimization of established systems through modern management methods. Development of the business environment has caused change in the structure of manufacturing processes and the scope of overhead activities, which have been reflected in an increased differentiation of overhead costs. The complexity of the relationships and causes of costs is becoming so significant that traditional costing methods do not provide sufficient information, creating the need to seek a more sophisticated costing system. The Activity-Based Costing method calculates costs according to activity. The principle of calculation is the allocation of overhead costs to individual defined activities, through which they are assigned to cost objects on the basis of a causal relationship between the economic resource and the cost object. The paper presents modern cost management tools with a focus on the Activity-Based Costing (ABC) calculation method and its application in the field of foundry production. The aim of the paper is to present the implementation of the ABC method through a case study in a selected industrial enterprise and to emphasize its further important role in the management of activities implemented in the enterprise and for the restructuring of company processes and activities.
\end{abstract}

Keywords: Activity-based costing, cost management, calculation methods, metallurgy

\section{INTRODUCTION}

The acceleration of economic cycles and globalization of the market are placing ever-increasing pressure on the competitiveness of companies. Therefore, it is necessary to systematically build a competitive advantage in the area of cost management. Traditional costing concepts based on the relationship between cost and volume may not necessarily provide the right signal for resource allocation, pricing and product selection. With the exception of direct production costs, the traditional calculation system does not create the correct scheduling basis for the allocation of overhead costs. The criteria of traditional systems were satisfactory in the 1960s, when direct costs (labour, wages, direct overheads) were key forces in business. The instability of the business environment has led to changes in the structure of production output consistent with the nature of costs. The decrease in direct labour costs compared to the costs of production and support activities, which are not volume-dependent and therefore more difficult to quantify, means that serious distortions in the system of calculations may arise. A need arose to focus on cost developments in a broader context, and following the example of Japanese companies, to extend their interest and knowledge beyond the closed cost point to the enterprise as a whole [1]. These ideas are the conceptual basis of the Activity Based Costing (ABC) calculation method, which is based on the approach that the majority of the company's normal activities exist to support production, marketing and delivery of the product to the customer. Adopting an accounting concept based on the product life cycle leads to the conclusion that all costs should be attributed to the product which generated 
them. The method seeks to determine the true cause of costs and transforms the logical relationships between costs and outputs of the company into a calculation system. The ABC method originated in the 1980s in the United States and is associated with the names Kaplan, Cooper and Johnson. The extent to which the calculation concept has been used in business practice has been examined in several studies which showed that foreign companies use this model to a much greater extent than companies in the Czech Republic [2].

This paper presents the use of the modern $A B C$ calculation method in foundry production through a case study. The aim of the paper is to describe the individual steps in implementation of the method in a selected foundry with the intention of determining the structure of a cost sheet for quantifying the costs of a cost object (product).

\section{FOUNDRY PRODUCTION}

Casting is a method of manufacturing parts or articles in which molten metal or other molten material is poured into a mould whose cavity has the shape and size of the future product. The product created by solidification of liquid metal in the mould is called a casting. The casting can sometimes be a finished product or part, or it can be machined even further [3]. We can cast the casting into a foundry mould. This form can be permanent or non-permanent.

To make the mould, a model device (model and cores) is required. The device aids us in achieving the desired casting shapes. Castings are most often cast in non-permanent, disposable moulds (made from sandstone or a ceramic mixture) or in permanent moulds (metal moulds). Besides these, semi-permanent moulds also exist into which more than one piece can be cast, but after each casting, the mould needs certain modifications. When casting into non-permanent melds, a model corresponding to the outer surface of the casting, which is formed by its moulding and re-extraction from the moulding mixture, is required. The inner cavities of the casting are formed by cores, which must be made in special core boxes. Although casting into permanent moulds, especially for non-ferrous metals, is becoming increasingly important, casting into non-permanent, disposable moulds remains the predominant technology. Non-permanent moulds are made of moulding material and are destroyed after casting [3].

Moulding materials usually consist of three components: slags, binders and additives. The slag forms the basic skeleton of the moulding material and consists of grains larger than $0.02 \mathrm{~mm}$ [4]. It determines the basic properties of the mixture, especially compaction, breathability and chemical and thermal resistance to molten metal. The material most frequently used as slag is Quartz (silica - $\mathrm{SiO}_{2}$ ), which is the main component of natural sands.

A binder is a substance or mixture of substances which forms the binder system of a moulding mixture which finely spreads over the individual grains of the slag and binds them together. Both organic and inorganic binders can be used, but physical principles such as magnetism, vacuum or freezing can also be used to bond the mixture. The remaining moulding materials are additives which improve certain properties. These may be carbonaceous substances and substances which improve the plasticity properties of the mixture. Carbonaceous substances (most often ground black coal) are added to bentonite moulding compounds for raw moulds for cast iron castings. These substances prevent the metal from penetrating between the sand grains and thus improve the surface of the casting. Plasticizers (glucose, lye) improve the plastic properties of the mixture and its breathability [3].

Filling of the mould cavity is provided by the inlet system, which consists of the following parts: inlet (casting) hole, inlet channel (pole), impact hole, slag remover, notches. Molten metal is poured into the inlet well. Its shape allows the reduction of metal spatter, but also the separation of slag due to the impact hole. The inlet channel usually has a circular cross-section. The inlet channel tapers slightly downwards to follow the shape of the free-falling metal stream. The slag remover distributes the liquid metal from the inlet channel to the individual notches and serves to catch the impurities [4]. Recently, ceramic filters have also been used to 
improve the removal of slag and macroscopic inclusions to trap impurities. The notches connect the slag remover to the mould and ensure the distribution of liquid metal into the mould.

\section{THE ABC MODEL CONCEPT}

The basic philosophy of the calculation is to assign costs according to activities. To assign costs to objects, the method measures the actual physical performance of the activities performed. The essence of the ABC calculation is the allocation of indirect costs to individual activities through which they are assigned to cost objects based on the causal relationship between the financial source and the cost object. From a methodological point of view, this is a full cost calculation (the so-called absorption method), which can be combined with the non-absorption method [5]. The process of creating an ABC model can be divided into several basic stages.

The first basic stage is the identification of activities and processes which take place in the company. The principle should be observed that the process is a logically consecutive sequence of activities and that each activity must be limited in time and materiality. In an analysis of processes, it is appropriate to create a pyramid structure of these processes. Each element of the basic level has its reference quantity called cost driver, which defines the method of conversion of costs from accounting to individual activities [6]. The basic precondition for success in defining the structure of activities is that it will reflect the process hierarchy of activities and not the functional arrangement in the company. In addition to hierarchical division, activities can be divided into main and supporting areas. The second strategic step of this stage is the definition of cost objects, which should be done consistently with the definition of activities to ensure the continuity in application of the $A B C$ system. At the end of the stage, it is appropriate to create a visualization of the structure of activities with a representation of their interrelationships.

In the second stage, the spent economic resource (indirect cost) is assigned to individual activities based on a relational cost variable called the Resource Cost Driver [7]. The aim is to quantify the costs arising from undertaking individual activities. As part of the cost valuation of activities, the transformation of cost items from the accounting records and their assignment to individual activities must be performed. This transformation can be performed using the so-called activity cost matrix, which captures the links between cost types and defined activities. The output of this matrix is quantification of the total costs of individual activities. This is followed by the determination of relational quantities of activities, which represent a measure of the performance of a given activity. The selected relational quantity should capture the causal relationship of costs to the performance of the activity and should be determined so that it can be quantified on the basis of data available within the company. The activity ratio should be measurable to determine the activity performance rate. The last step of this stage is calculation of the unit cost of the activity, which shows the amount of cost associated with the performance of one unit of the identified activity. The final stage is assignment of the costs of activities to the cost object, for example, performance, service, customer [5].

\section{IMPLEMENTATION OF THE ABC METHOD IN METALLURGY}

The aim of the case study was to describe the implementation of the $A B C$ method in foundry production. The study was performed at a foundry company, which is among the "small enterprises", based on the criteria for assessing the size of a company (according to Recommendation 2003/361/EC). The foundry's production programme is focused on piece and small series production of steel castings (unalloyed, low-alloyed), flake graphite cast iron (FG, Grey Iron), spheroidal graphite cast iron (SG Iron) and non-ferrous metals (aluminium and copper alloys). Products are manufactured on the basis of customer demand. The above production programme implies the complexity of the relationships and causes of costs. The growth of cost differentiation showed that the traditional calculation method has insufficient informative value for cost allocation, and therefore the use of the modern ABC calculation method was proposed. Implementation of the method was divided into three basic phases: analysis, model creation and commencement of operation. In the first phase, 
the reasons for implementation were defined, and the structure of the $A B C$ model was then determined. A strategic model was chosen - characterized by a lesser number of activities - to which are assigned the costs incurred over a longer period. In the next step, an analysis of the implementation costs was performed, and the expected outputs of the system were defined. The second phase was creation of the model, which included implementation of the individual steps of creating the ABC system. In the third phase, the system was put into operation, and automated data acquisition and processing was addressed to ensure its complexity. Due to the limited scope of the paper, only the second phase is presented in the following section, which describes the individual steps in implementation of the $A B C$ method in the company.

\subsection{Creation of the Model}

Prior to the commencement of work on creating the model, an adjustment of accounting data was performed. Adjustment of the accounting data is necessitated by the difference between the financial and managerial concept of costs. The general effort of the first phase of model creation is to capture the real economic nature of the resources consumed. In the absence of adjustments, there is a risk that the costs associated with the activities may be distorted to some extent. First, specific accounting costs were excluded, such as exchange rate differences, gifts, provisions, re-invoicing, etc. However, the system included costs which are not recorded in the accounts, so-called calculation costs (e.g., calculation depreciation).

\subsubsection{Definition of the Structure of the ABC System}

In the first phase of implementation, the company's activities and cost objects were defined. The following criteria were decisive in the identification. The selected foundry is a small enterprise whose production programme focuses on piece production with a high proportion of manual labour. Wages represent the highest cost item. In cooperation with a consulting company, the technological process was divided into individual production activities represented by human labour. The aim was to map the volume of human labour devoted to individual activities. Based on these steps, the structure of activities was determined. Through analysis of the technological process, 14 primary activities were identified which mapped the basic production operations and human resources (e.g., core production, moulding, extrusion of castings, finishing of castings, separation of inlets and risers, blasting, annealing, grinding, etc.). In defining the structure of primary activities, the individual activities were assigned an identification numerical code and a precise description of the activity was specified and then applied to the new information system. The numerical code assignment system was based on the principles set by the software with a link to production processes and planned automation of data collection. The created structure of primary activities with an abbreviated description of activities is shown in Table 1. The next step was specification of the so-called support activities, which represent the activities performed to enable operation and provide the overall infrastructure of the company. Activities which were not assigned to primary activities were divided into related groups. Ten support activities were identified (e.g., purchase of materials, metallurgical preparation, technological preparation, personnel activity, economic activity, maintenance, etc.) in terms of their significance and cost generation. For the sake of transparency, a graphical visualization of the structure of assets and their interrelationships was performed. Finally, a cost object was identified, namely one product (casting).

Table 1 Example of the structure of primary activities at the selected foundry

\begin{tabular}{|c|c|c|c|}
\hline \multicolumn{2}{|c|}{ STRUCTURE OF PRIMARY ACTIVITIES } \\
\hline Centre code & Activity code & Activity name & Description of activity \\
\hline 651 & F110 & Core production 3165 & Manual production of cores in the steel department \\
\hline 675 & F500 & Extrusion of castings & Extrusion of castings and sand from moulds \\
\hline 676 & F600 & Finishing of castings & Manual removal of sand from castings \\
\hline
\end{tabular}




\subsubsection{Allocation of Costs to Activities}

The next stage in creating the model was the allocation of costs to activities with the aim of quantifying the costs caused by the actions of individual activities. The company's total costs are divided into direct, wage, variable and fixed. Direct costs are allocated to the cost object in the final phase of implementation. Wages and variable costs are assigned to individual primary activities, and fixed costs to support activities. Typesorted costs are imported from the accounting system, including analytical accounts and centres, which are created according to activity into a special application in the software. Using the so-called activity cost matrix, the costs, broken down by type, are transformed into calculation costs. Costs are allocated to activities based on a cost relationship called the Resource Cost Driver, in the form of direct allocation where a real relationship between the cost and the activity exists. For example, in the accounting, labour costs are directly attributed to activities using cost centres. Other representatives of the reference quantities used are units of measure, time analysis of work performance and quantified estimates. For example, a ratio - the number of regular employees and the total number of employees for an activity - is used to allocate agency worker costs. When allocating petty overhead material costs, a percentage allocation to activities is used. The output of this matrix is quantification of the total indirect costs for individual activities (Cost Pool). The activity cost matrix works with analytical accounts, which are further classified according to their nature into variable and labour costs due to the subsequent breakdown of unit costs of activities. The Activity Cost Matrix of primary activities (CPA), which are divided into variables (VC) and wages (LC), is shown in Table 2. The next step in this stage was to assign costs to support activities. The nature of these activities does not allow them to be assigned directly to cost objects. Their performances are not consumed by products, but by primary activities. If the causal relationship between the cost and the cost object is to be maintained, the costs of the support activities are allocated through the primary activities. The procedure was as follows. The company's fixed costs were allocated to support activities on the basis of the cost ratio. Furthermore, they were quantified so that they could be assigned to primary activities according to the procedure described in the following chapter (see 4.1.3). The identified costs of support activities were allocated to primary activities using a software application, the so-called activity cost matrix. For example, depreciation of assets based on the company's decision was not assigned directly to the primary activities, but not until this stage, through support activities. The costs of support activities were allocated according to the time consumption (relative quantity of the minute) on the principle of the Time-Driven Activity Based Costing method [8]. The activity cost matrix captures the allocation of primary activity costs (CPA) broken down into variable costs (VC) and labour costs (LC), and for individual activities, support activity costs (CSA), see Table 2 .

Table 2 Example of Activity Cost Matrix (in CZK thousands)

\begin{tabular}{|c|c|c|c|c|c|}
\hline \multicolumn{6}{|c|}{ ACTIVITY COST MATRIX } \\
\hline \multirow{2}{*}{ Activity code } & \multirow{2}{*}{ Activity name } & \multicolumn{2}{|c|}{ CPA } & \multirow{2}{*}{ CSA } & \multirow{2}{*}{ Total } \\
\hline & & VC & LC & & \\
\hline F110 & Core production 3165 & 209 & 792 & 86 & 1,087 \\
\hline $\mathrm{F} 500$ & Extrusion of castings & 80 & 793 & 48 & 921 \\
\hline $\mathrm{F} 600$ & Finishing of castings & 89 & 428 & 42 & 559 \\
\hline & Total & 378 & 2,013 & 176 & 2,567 \\
\hline
\end{tabular}

\subsubsection{Definition of Relationship Quantities and Calculation of Unit Costs for Activities}

The costs allocated to the individual activities (see chapter 4.1.2) are then allocated to the individual cost objects (castings). For these purposes, the performance of the activities should be measured and the relationship between the costs of the activity and the cost object should be expressed using these measures. For this purpose, the relational quantity of the activity is used, called Activity Cost Drivers (ACD). It represents 
certain causal factors which cause a change in the cost of the activity and a measure by which the performance of the activity is measured. For ACD measurement purposes, this should be quantifiable. In cooperation with the consulting company and the company's technical staff, the relationship quantities were determined for primary and secondary activities. In the case of 11 primary activities, a time quantity (minute) was determined, for example, for manual forming, core production, extrusion of castings, finishing of castings, separation of inlets and risers, grinding, etc. Other reference quantities were, for example, gross weight (annealing activity) or raw weight (blasting, melting activity). Furthermore, quantification of the number of consumed units of performance of individual activities was performed. To determine the number of units, standardization of time consumption was performed for all operations. A combination of different standardization methods was used, for example, the working day period, the analytical chronometric method, summary comparison method, statistical method, MTM / MOST principle method, etc. Multiple regression analysis of empirically obtained data was also performed to generate formulas for automated standardization. Based on the quantification of ACD, the degree of performance of individual activities was determined, called the Activity Recovery Rate (ARR). The unit cost of activities, the Activity Primary Rate (APR), was calculated, and the amount of costs per unit of the given activity was thus obtained. We determine APR as a proportion of total costs (Cost Pool) and ARR. Information about the amount of unit costs of activities is an operational tool for analysing the efficiency of the services performed. The APR for secondary activities was calculated in the same manner to obtain the secondary unit cost of activities (SAPR). Based on the procedure described above, the primary unit costs of activity (PAPR) were obtained. Due to the division of the total costs of primary activities into variable and wage costs, the primary unit variable costs of activities (PVAPR) and the primary unit wage costs of activities (PLAPR) were determined. The company uses all unit costs PVAPR, PLAPR, SAPR in allocating the costs of individual activities (processes) for casting; the sum of the total unit costs (APR) were obtained and are listed in Table 3.

Table 3 Example of calculation of total unit costs of activities (APR) in CZK/minute

\begin{tabular}{|c|c|c|c|c|c|}
\hline \multicolumn{6}{|c|}{ UNIT COSTS OF ACTIVITIES (APR) CZK/min } \\
\hline \multirow{2}{*}{ Activity code } & \multirow{2}{*}{ Activity name } & \multicolumn{2}{|c|}{ PAPR } & \multirow{2}{*}{ SAPR } & \multirow{2}{*}{ APR } \\
\hline & & PVAPR & PLAPR & & \\
\hline F110 & Core production 3165 & 1.48 & 5.59 & 0.63 & 7.70 \\
\hline F500 & Extrusion of castings & 0.81 & 3.37 & 0.15 & 4.33 \\
\hline $\mathrm{F} 600$ & Finishing of castings & 0.25 & 4.02 & 0.05 & 4.32 \\
\hline
\end{tabular}

\subsubsection{Allocation of activity costs to cost objects}

The allocation of activity costs to cost objects is the final stage of overhead cost allocation to the product. The purpose is to quantify how many units of activity a certain product has consumed. We determine the total overhead costs of the casting based on the product of the consumed number of activity units and unit costs. The company has determined which activities each casting consumes, and further identifies criteria (according to standards, technological procedures, technical data), which automatically quantify the consumption of units of activities (min, $\mathrm{kg}, \mathrm{pcs}$ ). At the same time, the unit costs of activities are introduced in the system. Based on this data, the system automatically generates detailed structured overhead costs, which are assigned to specific castings

\section{PRODUCT CALCULATION SHEET}

The aim of implementing the $A B C$ method was to create a new calculation system, and the desired result was to design a calculation sheet for the product (casting). $\mathrm{ABC}$ is a full cost calculation. Chapter 4 describes the procedure for allocating overhead costs (activity costs) to products. To obtain the full cost of the products, the 
calculation included direct costs and non-allocable costs, for example, costs of advertising activities in the form of a percentage surcharge. The proposed calculation sheet is shown in Table 4, in abbreviated form. It shows the calculation of the total actual costs per unit of casting. Individual types of costs were calculated as the product of the number of units consumed (ARR) and the total unit cost (TUC), which is divided into direct unit cost (UDC) and unit activity costs (PVAPR, PLAPR, SAPR). The calculation sheet, including input source data, was implemented in the system. A calculation sheet is generated automatically, based on the input technical parameters of the product entered. In comparing the cost calculation according to the new ABC method and the original mark-up methods, significant differences in the allocation of overhead costs to individual castings were demonstrated.

Table 4 An example of a cast calculation sheet in abbreviated form (in CZK)

\begin{tabular}{|l|r|r|r|r|r|r|r|r|r|}
\hline \multicolumn{2}{|c|}{ CAST (1 unit) } & ARR & ACD & TUC & UDC & PVAPR & PLAPR & SAPR & Total \\
\hline Direct costs & Material ..... & 18.50 & $\mathrm{~kg}$ & $\mathbf{9 . 4 0}$ & 9.40 & & & & 173.9 \\
\hline Costs of activities & Manufacturing of cores & 23.20 & $\mathrm{~min}$ & $\mathbf{7 . 7 0}$ & & 1.48 & 5.59 & 0.63 & 178.6 \\
\hline F110 & Hammering of castings & 16.80 & $\mathrm{~min}$ & $\mathbf{4 . 3 3}$ & & 0.81 & 3.37 & 0.15 & 72.7 \\
\hline F500 & 12.83 & $\mathrm{~min}$ & $\mathbf{4 . 3 2}$ & & 0.25 & 4.02 & 0.05 & 55.4 \\
\hline F600 & Finishing of castings & & & & & $\mathbf{4 8 0 . 6}$ \\
\hline Total direct costs + activity costs & & & & & 33.6 \\
\hline
\end{tabular}

\section{CONCLUSION}

The foundry industry can be characterized as a high capital intensity field which allocates a large amount of funds to technology, technical equipment and environmental safety processes. This raises the need for effective cost management using modern methods. The change in the cost structure and the growing differentiation of overhead costs have shown the shortcomings of traditional calculation methods. Their concept based on the relationship between costs and volume does not create a correct scheduling basis for the allocation of overhead costs. The ABC calculation method provided a solution to this problem. The relationship between cost and performance is no longer formed on a distortive scheduling base but according to actual activities undertaken to create output. Domestic companies make use of the calculation concept in business practice at a much lower rate than foreign companies. The aim of the paper was to describe the application of the ABC method in foundry production. The set goal was achieved by presenting the individual implementation steps of the method and creating a cost sheet for quantifying the costs of the cost object. In conclusion, it should be emphasized that the method provided a wide range of information which can be used in managing business activities and restructuring business processes and activities.

\section{ACKNOWLEDGEMENTS}

The work was supported by the specific university research of the Ministry of Education, Youth and Sports of the Czech Republic No. SP2021/71.

The article was created thanks to the project No. CZ.02.1.01/0.0/0.0/17_049/0008399 from the EU and $C R$ financial funds provided by the Operational Programme Research, Development and Education, Call 02_17_049 Long-Term Intersectoral Cooperation for ITI, Managing Authority: Czech Republic Ministry of Education, Youth and Sports. 


\section{REFERENCES}

[1] DOYLE, D. Cost Control. London: CIMA Publishing, 2002.

[2] POPESKO, B. Moderní metody rǐzení nákladů. Praha: Grada Publishing, 2016.

[3] ELBEL, T. Základy slévárenské technologie. Ostrava: Vysoká škola báňská - Technická univerzita Ostrava, 2006.

[4] ČAMEK, L., FABÍK, R. Metalurgické technologie. Ostrava: Vysoká škola báňská - Technická univerzita Ostrava, 2013.

[5] KRÁL, B. Manažerské účetnictví. Praha: Management Press, 2006.

[6] STANĚK, V. Zvyšováni efektivnosti procesním ř̌zením nákladů. Praha: Grada Publishing, 2003.

[7] HADLAW, M., ZABINSKI, T. A new perspective for the application of the Activity Based Costing method in manufacturing copmanies using MES class systems. Bussines Informatics. 2020, vol. 2, no. 56, pp.30-42.

[8] VEDERNIKOVA, O., SIGUENZA-GUZMAN, L., PESANTEZ, J., ARCENTALES-CARRION, R. Time-Driven Activity-Based Costing in the Assembly Industry. Australasian Accounting Business \& Finance Journal. 2020, vol. 14 , no. 4, pp. 3-23. 